\title{
Local Community Intelligence, Wellbeing and the Potential Role of Web 2.0 Applications
}

\author{
1 Rachel Keller \\ Highwire \\ Lancaster University LA1 4YW \\ r.keller@lancaster.ac.uk
}

\begin{abstract}
Web 2.0 applications offer some interesting possibilities for the Collective Intelligence (Cl) of Local Communities. Local Communities typically have limited resources and technological know-how to fully exploit the features of Web 2.0. However, their usually diverse mixed demographic may be advantageous in community intelligence and decision making with implications for Wellbeing. Evidence shows a mixed range of knowledge and perspectives is often superior to expert opinion. This could confer particular benefits for Local Communities. This paper suggests that individuals within Local Communities may be very receptive to increased community engagement, outlines the need for a taxonomy to maximise the outcomes of Collective Intelligence (CI), speculates about some possibly rich seams for future research and some expedient ways of doing this through the use of Web 2.0 applications. In doing so there is consideration of contributions from Computer Science, Management and Design.
\end{abstract}

Web 2.0 Applications; Collective Intelligence; Diversity; Social Innovation; Wellbeing.

\section{INTRODUCTION}

Collective Intelligence refers to the processes and applications of harnessing knowledge and opinion distributed across individuals. In the case of Local Communities we are interested in deriving positive outcomes for geographic areas such as villages, towns and cities. Individuals within the Community don't necessarily need to know each other to benefit. In some cases being influenced by others opinions can be detrimental. Nor are we suggesting that individuals need necessarily to have particular intelligence to contribute. Decisions based on a broad range of knowledge and opinion is often superior to expert decision. Page used a computer modelling system to demonstrate that groups with diverse skills and outlooks arrived at smart solutions more often than groups of very clever people who shared the same outlook and skills 'as long as they are organised in the right way'.

This paper emphasises that the range, content and type of decision are so varied, that 'one size doesn't fit all'. Instead of trying to decide the 'victor' from the competing models, it may be more useful to start developing a taxonomy of what kinds of decision making process may be best suited to what situation. Of particular interest is the role for Web 2.0 Applications. The plethora of commercial applications compares to a paucity of Applications based on Physical Communities such as Local Communities.

There are some compelling and timely factors for considering the role of Collective Intelligence in improved outcomes for Local Communities. The first is the growing appetite for Web 2.0 Applications and the growing socio-technical affordances of the internet. Latterly we have seen the emergence of applications with more relevance to Local Communities although most not specific to Local Communities. For example, data.gov in the UK, challenge.gov and Code America in the States.

The second factor is the challenges and appetite to address economic issues and those of sustainability. Third is the recent national focus on community as a mechanism for enhancing quality of life and addressing social ills and lack of resources for an acceptable standard of living.

This paper draws on research in Management, Design and Computer Science. In the view of this paper, knowledge management has shortcomings highlighted by many researchers, for example, underutilisation of the tools that already exist, and lack of engagement due to not considering how human sensitivities can be accommodated. We propose the concept of 'Collective Intelligence' as the framework for progressing 'knowledge 
management' and applying it to Local Communities. This does not mean another competing model of knowledge management. Rather, it means a framework, the start of a taxonomy enabling a 'mix and match' approach to achieving the best outcomes from Collective Intelligence.

There is an issue of the scope of such a taxonomy. For example, some individuals have great insight, prescience or intuition? For Community Wellbeing it would be advantageous to identify and harness these contributions for everybody's benefit. Collective Intelligence need not mean that for every occasion many people have to contribute. Collecting Intelligence could mean using any ethical and practicable way of accessing and making use of information.

The starting point for developing a taxonomy may be to identify stages of Knowledge Management. This paper proposes a five stage model consisting of gathering information, organisation of information, decision making, execution and evaluation. This does not assume that all five stages always take place as distinct and different processes. For example, it is conceivable that effective organisation of information (stage 2) may naturally yield the best decision (stage 3) and so the two stages may merge. Voting would be an example of this.

Another consideration is that of the emotions. The Feldmen paper outlined later makes little mention of this explicitly. However, one has to consider that the 'best' algorithm in the world may give the 'best' outcome for a community but the manner in which it is arrived at, and the outcome itself although rational, may not sit happily with Community members. Furthermore, all the theory is the world is insufficient if Local Communities have little appetite for more engagement, a probable pre-condition of achieving the benefits of Collective Intelligence to Local Communities. Unless the community can be engaged, with its wide ranging demographic, the potential benefits are significantly capped.

The following sections outline approaches to Knowledge Management, considers 'Crowd Intelligence', outlines some emerging Local Community applications, highlights YourVoice (an initial assessment of appetite for engagement), some work on Open Source, research on the promise of Serendipitous connections and access points to enable full community participation.

\section{KNOWLEDGE MANAGEMENT}

Langley and colleagues (1995) outline the theories polarised as those with rational, clear sequential staged processes at one end such as that of Simon , and at the other end of the spectrum is a 'focus on organizational decision making as a social interactive process originating from (March, 1962) and a range of others and developed within a stream of "political" models emphasising individual self interest through processes such as bargaining, coalition building, persuasion'. The 'Garbage Can Model' (Cohen et al., 1972) was possibly the most extreme in describing organisational decision making as chaotic. In the view of Langley et al (1995) 'it could be used as a dumping ground for unexplained variance in decision making and anarchic processes on the other'.

Langley and colleagues (1995) comment on the 'ambiguities that surround the relationship between commitment and action'. 'While the concept of "decision" itself (which we take to mean commitment to action) may imply distinct, identifiable choice, in fact many decisions cannot easily be pinned down, in time or in place.....'even when a decision can be isolated, rarely can the process leading up to it'. Furthermore 'action can occur without commitment to act. This is compounded by the decision making process comprising many dynamic linkages 'interwoven networks of issues'. They re-conceptualise Decision Processes as 'Issue Streams' to reflect the reality of how decision making occurs in organizations and to acknowledge that decisions interact with one another. Indeed this may be more akin to the notion of wicked problems (Rittel and Webber, 1973). These can be which can be described as problems that are difficult or impossible to solve due to incomplete, contradictory or varying needs. Interdependence is recognised and the consequent solving of one problem unveiling or creating other problems.

Langley and colleagues (1995) challenge the idea that 'organisational decisions are identifiable outcomes of impersonal and isolable processes' overlooking the role of 'emotion, imagination, and memories of the decision makers and are punctuated by sudden crystallizations of thought'.........' In addition to 'cerebral rationality' the decision maker is extended to affect, inspiration and insight'. They assert that traditional analyses have overlooked human factors and individual characteristics that 'combine to determine organisational outcomes' ..... 'insight might be dismissed as too rare to command attention were it not for evidence that 'a great deal of the behavior of organizations is determined by those occasional insights that restructure thinking' or what some researchers may call a paradigm shift.

Burley and colleagues (2010) advocate developing the current knowledge management discourse from a focus on the more mechanistic roles of 
knowledge management systems (e.g. bridging information silos) toward new horizons of knowledge inquiry using next generation tools. Current knowledge management systems neither exploit the capabilities of high performance computing, nor adequately address organizational challenges presented by increasingly knowledgeladen, dispersed, global organizations'. Although Local Communities differ in some respects, for example, they are by definition not geographically dispersed. They do however, share the commonality of knowledge distributed throughout individuals. Both potentially benefit from effective processes for harvesting, organising and applying this information. It would be foolish not to learn from both the successes and failures in the Management field. This paper outlines some of the processes for harnessing such knowledge and extends this beyond the field of Management suggesting that in terms of the potential, such processes are at an early stage of development.

\section{CROWD INTELLIGENCE}

In the past few years, we've seen a powerful interest in and adoption of bottom-up and collaborative approaches to problem-solving and decision-making. Under the right circumstances, these approaches can be extremely effective, and can yield solutions that are consistently better than those produced by the smartest expert even when individuals are not influenced by each other. Groups, instead of falling to their lowest common denominator may rise beyond the level of their best member.

Often decisions are made by groups of people. The converse is 'crowd' intelligence, typified by independent persons, often unknown to each other but always uninfluenced by each other. This kind of decision making process has its own shortcomings such as 'GroupThink.' The converse is 'crowd' intelligence, typified by independent persons (uninfluenced by each other), unknown to each other and without face to face contact. We do not advocate any one method but rather feel this offers scope to develop a model and taxonomy of what kinds of information harvesting, organisation and application have the best outcomes and in which situations. (Leadbeater, 2008) says that 'Crowds and mobs are stupid as often as they are wise'. 'It all depends on how the individual members combine participation and collaboration, diversity and shared values, independence of thought and community. When the mix is right ..... the outcome is a powerful shared intelligence. When the mix is wrong it leads to cacophony or conformance'.

In 'The Wisdom of Crowds', Surowiecki (2004) gives many compelling examples of crowd decisions surpassing expert opinion starting with the respected statistician and polymath, Francis Galton. He collected the voting slips from the 787 local townspeople voting on the weight of an ox. The average crowd guess was 1198 and the actual weight was 1197 pounds. Enough people eliminate spurious extremes. Surowiecki outlined four essential components of a wise crowd, that is, diverse collections of independently-deciding individuals and not crowd psychology (ordinary people can typically gain direct power by acting collectively). The first component is diversity of opinion: each person should have private information even if an eccentric interpretation of the known facts. The second is Independence : people's opinions aren't determined by the opinions of those around them.

The third is Aggregation : Decentralisation's real weakness is knowing whether key information will be disseminated. It works well in only some conditions. Aggregation may be the answer rather than centralisation. Tapscott and Williams (2008) refer to organisation failure to harness the crowds. They ask about the circumstances in which it is best not to control and cite Yahoo which used to employ taxonomists but whose need for them diminished over time as naturally occurring taxonomies formed. The fourth is that some mechanism exists for turning private judgements into a collective decision.

\section{EXAMPLES OF COMMUNITY APPLICATIONS}

'Voice Your View' (vYv), focuses on making public spaces safer (Nasa et al., 2010). The mechanism is via mobile and static devices that allow the public to voice their opinions and concerns on their environment thereby capturing the idea before it is forgotten. A key part is the use of advanced natural language processing algorithms to filter, structure and derive meaning from potentially enormous amounts of data. An early trial of 600 users showed an acceptable theme in a comment was identified $78 \%$ of the time.

They have also looked at public perception maps by automatic text analysis of verbatim responses from a public consultation of police satisfaction and confidence organised by the Derry District Policing Partnership. The results show an accuracy of $70 \%$. The authors point out how these developments accord with Gov 2.0 developments for citizen empowerment aimed at giving them 'simple ways of using technology to report problems, engage with local government, or become more integrated with their community'. Other examples include SeeClickFix where 'You're just one click away from raising awareness about issues in your neighbourhood' and aspires to encourage active 
citizenship, by offering a variety of platforms to report concerns using the website, mobile applications, widgets and Voicemail.

\section{YOUR VOICE}

During 2010 we trialled a Design for Web 2.0 applications on a Local Community. Initial user testing was on 14 people. Aware of the benefits of Diversity we attempted the challenge of a Universal Design, that is, one that would appeal to different demographics and reduce barriers to access. We conjoined a different range of Web 2.0 applications to those normally seen, visualised the 9 applications with a naturalistic style, and incorporated 'Status Icons' as a metaphors for the state of health of the community. Evaluations on a further 6 potential users ranged across a nineteen year old Computer Science student through to an eighty year old having never used a computer. This demonstrated a high intent to use the design. Although this merits further assessment with a greater number of users, the unexpected levels of interest demonstrates a Universal Design may be an achievable first step of increased Community Engagement. That said, this is only one of a range of possible ways of Community involvement.

YourVoice was the Application offering most scope for Community Engagement and offering one method of harvesting community intelligence. Initial user testing showed that 11 of the 12 responding said they would possibly, probably or definitely use the application. Comments included 'It's a good forum to express your ideas. I might chat to a friend but that is not going to make things happen. Sometimes things happen without it going through the community.....it goes through the committee rather than grass roots'
In the next stage of development, with more dynamic content, it would be interesting to see the popularity of particular actions according to different demographics and extra weighting given to community members not normally involved in community decision making. Empathy is a key factor in behavioural change. Being able to appreciate others perspectives may lead to voting based on overall good rather than personal interest. We are not advocating that final voting weights certain demographics more heavily, rather that final voting may be influenced by consideration of voting preferences of others.

Here is a real life example. $\mathrm{X}$, a full time working parent, was asked to vote whether it was acceptable for her children's school to close at lunchtime before each school holiday. For herself and the few other full time working parents this was very disruptive. Most parents voted that they did not mind if the school closed at lunchtime. As having both parents working full time was a minority at this school, the vote was carried. Had the parents for whom it wasn't an issue been aware of the consequences for the minority parents they would have the opportunity to develop some empathy and change their vote. In terms of an Application such as YourVoice, the actual process of voting could potentially be labour saving and based on appreciation of the consequences of an action for different segments of a population - an informed and meaningful choice. Many parents who didn't work full time, would not have voted when they became aware of the implications. What is more, the argument can be made that removing oneself from the scrutiny of returning a voting slip in person, at odds with outcome the school desired, added a level of impartiality.

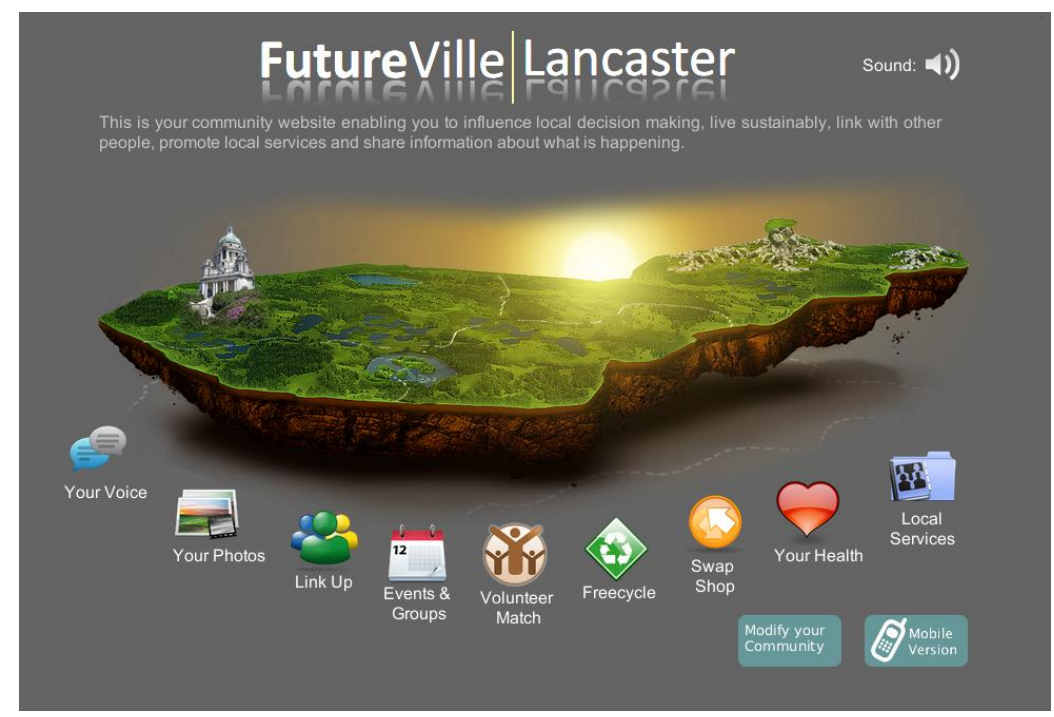

Figure 1: Homepage Design Illustrating Content and Style http://futureville.uphero.com 


\section{OPEN SOURCE AND DESIGN}

Feldman say that 'Some significant subset of social problems that confront communities are or can be constructed as knowledge creation and/or problems solving similar to the problems that the open source software community has found new ways to solve. It follows that the tools and governance principles of the open source community software community, in some modified form, could yield new approaches to community building and problem solving'..... 'give non technical people tools to joining their forces to solve their relevant social problems'. He says 'skills are very rarely joined together' but remain distributed but not united. They suggest the possible application is vast and covers economic, social, health and civic areas.

They aim to design a system with many features, four of which are outlined as follows. The first is to have effective individual incentive, organisational structures and information technology tools. The second is to pull together distributed knowledge within communities that are trying to solve practical problems combining them into something useful. Third is to ensure that error correction exceeds the rate of error introduction as the system learns. The fourth is to maintain the process sustainably, non exploitatively and expandably. New knowledge is not precluded, however; the initial focus is on the information processing issues which include algorithms and the associated structures and incentives that make the algorithm function in the real world. This raises issues such as when there would be a case for identifying and weighting particular contributions, or contributors. Presumably this would be based on a more objective analysis of the value of the contribution than that which normally happens such as from those with higher status or more perceived rather than actual expertise.

The Design Principles include designing for evolution; dialogue between inside and outside perspective; flexibility for different levels of participation; a focus on the value that is created for the people in the community and an amalgam of the familiar and the new.

\section{SERENDIPITOUS CONNECTIONS}

These offer interesting possibilities for symbiosis between unlikely people and between unlikely information. The basis of these connections between people is usually perceived similarity and proximity as previously highlighted in work by Festinger and colleagues (1963). However there is a dark side to this process. For example, cliques with their excluding behaviour, GroupThink, discrimination against people that are different, and, filtering out opportunities to develop connections with unlikely others, or, unlikely information. (Passant et al., 2008) say 'Cliques limit the possibility for people to make interesting new acquaintances and acts as a retarding force in the creation of new links in the social web. Encouraging users to socialize with people they don't know by revealing hidden surprising links ("surprising" relationships) could help improve the diversity of interactions'. This was validated with a Flickr community with the suggestion that if such connections could be mined 'they may form a catalyst for people at the event to forge new relationships'..... 'It is worth noting that surprising relationships suggested from the electronic traces and detritus that people leave in their electronic wakes may be both negative and positive'.

During information seeking one is normally guided by known terms and potential sources of relevant knowledge application rather than the unknown. 'You don't know what you don't know'. An unfortunate example is the invention of Gelignite by Alfred Nobel, when he accidentally mixed collodium with nitroglycerin. (Toms, 2000) says 'Information acquisition is generally thought to be deliberately sought using a search or query mechanism or by browsing or scanning an information space. People...... find information without seeking it through accidental, incidental or serendipitous discoveries'...... Although largely ignored in information systems development and research, serendipitous retrieval complements querying and browsing, and together they provide a holistic, ecological approach to information acquisition and define the key approaches to a digital library'. ......While significant evidence exists to support the value of serendipitous experiences, few information systems support such an method.

\section{ACCESS POINTS}

As diversity is such as key factor, to ensure inclusion from a wide demographic, this could mean some interesting possibilities for interfaces other than standard computers used in home settings. For example mobile phones, and publicly shared access points in a multiplicity of places including those such as doctors surgeries or hairdressers where the time challenged and those most likely to be time challenged or digitally compromised may have opportunity to engage.

\section{THE WAY FORWARD}

Different disciplines have a range of contributions to make, not least, Management has a track record 
of development and testing of knowledge management systems, Design is extremely mindful of and skilled in the use of engaging users and Computer Science offers Web 2.0 tools. Combining best practice from a variety of disciplines should be useful in considering the 'mix'. The multiplicity of theories, approaches, types of information and decision making process lend themselves to the conclusion that one theory may be insufficient and a taxonomy may help decide what approach is most suited to which situation.

Variables may include time scale, resources, complexity of information, level of consultation dictated by democratic principles, levels of interaction between individuals and critical numbers needed to make a decision. For example, Crowd Intelligence relies on large numbers. There may be certain situations where expert opinion at least equals that of the crowd and it may be resource light for this method to be employed. In such an instance, the Delphi method may help improve the outcome (Rowe and Wright, 2001). In some situations by using Web 2.0 Applications there may be a 'natural selection of the most effective approach. For example, Social Media mining can reveal the spread of epidemics quicker than official bodies can report, and more localised effects are showing promise with regards to rising river levels and other localised emergencies.

\section{CONCLUSION.}

Individuals comprising Local Communities have a wealth of information which could increase Wellbeing. This paper proposes more effective use of Collective Intelligence. It is suggested that the there is no one 'superior' method. The time may be opportune to start developing a taxonomy to help identify and select the most effective method given a particular set of circumstances. This has implications for identifying the variables determining the most effective way for information to be managed.

Thus a five stage model is proposed consisting of gathering information, organisation of information, decision making, execution and evaluation. The first step could be more rigorous identification of the different methods of Collective Intelligence with their respective strengths and weaknesses and the parameters within which they operate most effectively.

The growing popularity of Web 2.0 applications and the widespread affordances of the internet are offering expedient and interesting possibilities to take a key role within this taxonomy. It will be interesting to see how these applications develop.

\section{REFERENCES}

BURLEY, D., SAVION, S., PETERSON, M., LOTRECCHIANO, G. \& KESHNAVARZNIA, N. 2010. Knowledge integration through synthetic worlds. VINE, 40, 71-82.

COHEN, M. D., MARCH, J. G. \& OLSEN, J. P. 1972. A Garbage Can Model of Organizational Choice. Administrative Science Quarterly, 17, 1-25.

FESTINGER, L., BACK, K. W. \& SCHACHTER, S. 1963. Social pressures in informal groups: a study of human factors in housing, London, Tavistock.

LANGLEY, A., MINTZBERG, H., PITCHER, P., POSADA, E. \& SAINTMACARY, J. 1995. Opening up decision-making: the view from the black stool. Organization Science, 260-279.

LEADBEATER, C. 2008. We-think, London, Profile.

$\mathrm{MARCH}$, J. G. 1962. The business firm as a political coalition. The Journal of Politics, 24, 662-678.

NASA, B., BINNER, J., SIMM, W., FERRARIO, M. A., WHITTLE, J., LAM, B. \& ZHAO, Z. 2010. VoiceYourView: mapping public confidence in policing [Online]. Available: https://horizon.ac.uk/images/stories/f48Nasa.pdf [Accessed 10 January 2011].

PASSANT, A., MULVANY, I., MIKA, P., MAISONNEAUVE, N., LÖSER, A., CATTUTO, C., BIZER, C., BAUCKHAGE, C. \& ALANI, H. 2008. Mining for social serendipity.

RITTEL, H. W. J. \& WEBBER, M. M. 1973. Dilemmas in a general theory of planning. Policy Sciences, 155-169.

ROWE, G. \& WRIGHT, G. 2001. Expert opinions in forecasting: the role of the Delphi technique. In: ARMSTRONG, J. S. (ed.) Principles of forecasting : a handbook for researchers and practitioners. Boston: Kluwer Academic.

SUROWIECKI, J. 2004. The wisdom of crowds : why the many are smarter than the few and how collective wisdom shapes business, economies, societies and nations, London, Little Brown.

TAPSCOTT, D. \& WILLIAMS, A. D. 2008. Wikinomics: How mass collaboration changes everything, Portfolio Trade.

TOMS, E. G. 2000. Serendipitous information retrieval - Proceedings of the First DELOS Network of Excellence Workshop on Information Seeking, Searching and Querying in Digital Libraries [Online]. Available: www.ercim.eu/publication/wsproceedings/DelNoe01/3_Toms.pdf [Accessed 18 January 2011]. 